\title{
Plasma leptin and insulin-like growth factor I levels during acute exacerbations of chronic obstructive pulmonary disease Prokopis Kythreotis $^{\dagger 1}$, Ageliki Kokkini ${ }^{\dagger 1}$, Stavrina Avgeropoulou ${ }^{\dagger 1}$, Argyro Hadjioannou ${ }^{\dagger 1}$, Efgenia Anastasakou ${ }^{\dagger 2}$, Antonis Rasidakis ${ }^{\dagger 1}$ and Petros Bakakos*1
}

Address: ${ }^{1}$ Department of Respiratory and Critical Care Medicine, Sotiria Chest Hospital, Athens, Greece and ${ }^{2}$ Department of Microbiology, Immunology Laboratory, Sotiria Chest Hospital, Athens, Greece

Email: Prokopis Kythreotis - pkc@otenet.gr; Ageliki Kokkini - pkc@otenet.gr; Stavrina Avgeropoulou - stavrinavg@yahoo.gr; Argyro Hadjioannou - arghadjioanou@yahoo.gr; Efgenia Anastasakou - efganastasakou@yahoo.gr; Antonis Rasidakis - rasid@ath.forthnet.gr; Petros Bakakos* - petros44@hotmail.com

* Corresponding author †Equal contributors

Published: 5 April 2009

BMC Pulmonary Medicine 2009, 9:1 I doi:10.1 I86/147I-2466-9-1I
Received: 15 September 2008

Accepted: 5 April 2009

This article is available from: http://www.biomedcentral.com/I47I-2466/9/I I

(c) 2009 Kythreotis et al; licensee BioMed Central Ltd.

This is an Open Access article distributed under the terms of the Creative Commons Attribution License (http://creativecommons.org/licenses/by/2.0), which permits unrestricted use, distribution, and reproduction in any medium, provided the original work is properly cited.

\begin{abstract}
Background: Recent studies have provided evidence for a link between leptin and tumor necrosis factor-alpha (TNF- $\alpha$ ). Insulin-like growth factor I (IGF-I) mediates the metabolic effects of growth hormone $(\mathrm{GH})$. The $\mathrm{GH}$ axis is believed to be suppressed in chronic obstructive pulmonary disease (COPD). The aim of this study is to find out whether acute exacerbations of COPD are followed by changes in plasma leptin and insulin-like growth factor I (IGF-I) levels and furthermore, whether these changes are related to systemic inflammation.
\end{abstract}

Methods: We measured serum leptin, IGF-I, TNF- $\alpha$, interleukin I $\beta$ (IL-I $\beta$ ), interleukin 6 (IL-6) and interleukin 8 (IL-8) levels in 52 COPD patients with acute exacerbation on admission to hospital (Day I) and two weeks later (Day I5). 25 healthy age-matched subjects served as controls. COPD patients were also divided into two subgroups ( 29 with chronic bronchitis and 23 with emphysema). Serum leptin and IGF-I were measured by radioimmunoassay and TNF- $\alpha$, IL-I $\beta$, IL- 6 and IL- 8 were measured by ELISA.

Results: Serum leptin levels were significantly higher and serum IGF-I levels significantly lower in COPD patients on Day I than in healthy controls $(\mathrm{P}<0.00 \mathrm{I})$. A positive correlation was observed between leptin and TNF- $\alpha$ on Day I $(r=0.620, p<0.001)$. Emphysematous patients had significantly lower IGF-I levels compared to those with chronic bronchitis both on Day I and Day $15(p=0.003$ and $p<0.001$ respectively).

Conclusion: Inappropriately increased circulating leptin levels along with decreased IGF-I levels occured during acute exacerbations of COPD. Compared to chronic bronchitis, patients with emphysema had lower circulating IGF-I levels both at the onset of the exacerbation and two weeks later. 


\section{Background}

Weight loss commonly occurs in patients with chronic obstructive pulmonary disease (COPD) [1]. In a subgroup of COPD patients, weight loss is suggested to follow a stepwise pattern related to acute disease exacerbations [2]. Recently, cytokine-mediated metabolic derangements have been considered to be among the candidates responsible for weight loss in COPD patients $[3,4]$. It has been shown that tumor necrosis factor- $\alpha$ (TNF- $\alpha$ ) circulating levels are increased in weight-losing COPD patients $[3,4]$. COPD is characterized by a systemic inflammatory response that may be even more pronounced during an acute exacerbation of COPD [5].

Leptin, a protein synthesized by adipose tissue and encoded by the ob gene plays an important role in the energy balance and its circulating concentrations are proportional to the amount of fat mass (FM). Inappropriately increased leptin levels are thought to induce metabolic effects underlying anorexia and loss of body weight in chronic diseases including COPD [6,7]. Administration of endotoxin or cytokines such as TNF- $\alpha$ or IL- 1 produced a prompt and dose-dependent increase in serum leptin levels in both experimental animals [8] and humans [9]. In stable patients with emphysema, leptin was found to be positively related to plasma soluble TNF-receptor 55 [5]. The observed link between inflammatory cytokines and leptin led to the hypothesis that adipose tissue gene expression is regulated by inflammatory cytokines, which in turn could induce anorexia in acute or chronic inflammation.

Growth hormone $(\mathrm{GH})$ is secreted by the anterior pituitary and mediates its major metabolic effects through activation of somatomedins, predominantly insulin-like growth factor I (IGF-I) [10]. In COPD, little is known about circulating GH or IGF-I concentrations. Some authors found a decrease in GH or IGF-I, others an increase [11]. IGF-I levels tended to be lower in stable and hospitalized COPD patients due to an exacerbation [12]. IGF-I mRNA levels were decreased in muscle biopsies from hospitalized patients due to an acute exacerbation of COPD [13]. In animal studies, recombinant IGF-I has been shown to ameliorate the protein catabolism and promote anabolism observed under hypoxic conditions [14]. However, daily administration of rGH increased lean body mass but did not improve muscle strength in COPD patients [15].

In our study, we measured cytokine (TNF- $\alpha$, IL-1 $\beta$, IL-6 and IL-8), leptin and IGF-I levels at the onset of a COPD exacerbation as well as 15 days later. The aim of this study was to elucidate two questions. Firstly, whether COPD exacerbations are accompanied by changes in circulating levels of leptin and IGF-I. Secondly, whether plasma IGF-
I and leptin levels are related to those of cytokines as a possible reflection of the enhanced inflammatory status observed during a COPD exacerbation.

\section{Methods \\ Patients}

The patient group consisted of subjects consecutively admitted to our department due to an infectious exacerbation of COPD. COPD was defined according to GOLD criteria [16]. Irreversible chronic airflow obstruction was confirmed, i.e., $<10 \%$ improvement in FEV1 expressed as percentage of predicted after inhalation of a $\beta 2$-agonist. An infectious exacerbation of COPD was defined when at least two of the following three criteria were fulfilled: (a) recent increase in dyspnea (b) increased sputum volume and (c) sputum purulence, provided that one of the two criteria is purulent sputum [16].

All patients were current or ex-smokers. Patients with a medical history of comorbid diseases, such as diabetes mellitus, heart failure, lung cancer, collagen vascular disease or disturbances of thyroid function were excluded from the study. The final study group consisted of 52 patients (43 men, 9 women). The patients were treated with a standard protocol of medication consisting of nebulized short-acting $\beta 2$-sympathicomimetics (salbutamol), inhaled anticholinergics (ipratropium bromide) and intravenously administered prednisolone. Prednisolone was given in the same dose (50 mg) for 7 days and then directly stopped, without tapering the dose. Antibiotic treatment was given to all COPD patients for 7 days. During hospitalization 38 of the 52 patients received supplemental oxygen therapy, according to measured arterial blood gases.

The control group consisted of 25 healthy age-matched adults (19 men, 6 women). They had no medical illnesses, had normal physical examinations, blood counts, chemistries and showed no symptoms or signs of infection at the time of the study.

All participants were informed in detail of the characteristics of the study and written consent was obtained. The study was approved by the ethics committee of our hospital.

\section{Body composition}

Body height was determined to the nearest $0.5 \mathrm{~cm}$ with subjects standing barefoot. Body weight was assessed to the nearest $0.1 \mathrm{~kg}$ by using a digital weighing chair while subjects wore light clothing and no shoes. Body mass index (BMI) was calculated according to the equation BMI $=$ Weight $(\mathrm{kg}) /$ Height $^{2}\left(\mathrm{~cm}^{2}\right)$. Fat mass (FM) was measured with bioelectric impedance analysis with the portable device OMRON BF 302, (OMRON Healthcare Europe 
B.V, Hoofddorp). The basic principles of bioelectric impedance analysis were described by Lukaski and colleagues [17].

\section{Lung function}

FEV1 and FVC were measured with standard spirometric techniques (SPIRO 232 MORGAN, Model 435 P.K MORGAN, Ltd. Gillingham, Kent, England). Arterial blood gases were obtained once in healthy individuals and twice in COPD patients (upon admission and after 15 days) with the subject in the sitting position and breathing ambient air. Lung function values were expressed as a percentage of predicted [18]. Arterial blood gases were analysed on a blood gas analyzer (Rapidlab 855, Bayer Healthcare LLC Diagnostics Division, NY 10591, USA).

\section{Assessment of emphysema}

The distinction between COPD patients with predominant emphysema and those with chronic bronchitis was based mainly on high-resolution computed tomography (HRCT). HRCT is a sensitive technique for the evaluation of the presence and severity of emphysema. In patients with emphysema the densitometric parameters differ substantially from the corresponding values in patients with chronic bronchitis and healthy control subjects. Five thinsection CT scans were obtained in each patient: two scans of the upper, two scans of the lower lung zones at 3 and 6 $\mathrm{cm}$ above and below the carina and one scan at the carina. The severity and extent of emphysema of each scan was visually scored on a four-point scale independently by two observers according to the direct observational method of Sakai [19]. For each of the lung sections, the score for the severity of emphysema was multiplied by the score for the extent and the resultant scores were subsequently summed to give a total HRCT score. Visual scores ranged from 0 (no emphysema) to 120 (severe emphysema). Patients with a score $<30$ were subtyped as chronic bronchitis and patients with a score $\geq 30$ were subtyped as emphysema. According to this assessment the 52 patients with COPD were divided into 29 patients with chronic bronchitis and 23 patients with emphysema.

\section{Collection and analysis of laboratory and inflammatory parameters}

Blood samples were collected in the morning, between 8.30 and 9.30 AM, when patients were in the fasting state for at least $10 \mathrm{~h}$ twice in COPD patients (on hospital admission-Day 1, and 15 days later- Day 15) and once in healthy individuals. For the measurement of TNF- $\alpha$, IL$1 \beta$, IL-6, IL-8, leptin and IGF-I, blood was collected in plastic tubes containing ethylenediamine-tetraacetic acid (EDTA) and was centrifuged (1,000 $\times \mathrm{g}$ for $10 \mathrm{~min})$ within an hour. The supernatants were stored at $-70^{\circ} \mathrm{C}$ until analysis. Cytokines (TNF- $\alpha$, IL-1 $\beta$, IL-6, IL-8) were measured with ELISA (BMS 223/3, BMS 224, BMS 213/2 and BMS
204, Bender MedSystems, MedSystems Diagnostics $\mathrm{GmbH}$, Vienna, Austria Europe, respectively). Leptin and IGF-I were measured with radioimmunoassay (RIA, Active Human Leptin IRMA DSL - 23100, Diagnostic Systems Laboratories, Inc., USA and IGF-I 100 T KIT - Catalog No. 40-2100, Nichols Institute Diagnostics, USA, respectively). The lower detection limit of leptin was $0.10 \mathrm{ng} / \mathrm{ml}$. The intra- and interassay variation coefficient were 4.9 and $6.6 \%$ respectively. The lower detection limit of IF-I was $0.06 \mathrm{ng} / \mathrm{ml}$. The intra- and interassay coefficient were $3 \%$ and $9.8 \%$ respectively. All measured values for leptin and IGF-I were above the lower detection limit.

\section{Statistical analysis}

Data were expressed as mean \pm SD or as median (25-75 percentile) if they were not normally distributed. Statistical analysis was performed using nonparametric tests (Mann-Whitney U test for comparison between groups and Wilcoxon for comparison within groups). Dichotomized $\Delta$ was calculated by the formula $\Delta=$ D15-D1. Therefore $\Delta$ TNF- $\alpha=$ TNF- $\alpha$ D1-TNF- $\alpha$ D15, $\Delta$ Leptin = LeptinD1-LeptinD15 etc. The relations between continuous variables were evaluated with Spearman's rank correlation technique. Statistical significance was accepted at $\mathrm{p}$ $<0.05$. Data were analysed using SPSS (Statistical Package for the Social Sciences, version 14.0 for Windows, SPSS Inc, Chicago, IL).

\section{Results \\ Study group}

The mean age of COPD patients was $65.8 \pm 8.3$ years and the control group $65.9 \pm 9.6$ years. Clinical characteristics of the COPD patients (on admission-Day 1) and the healthy controls are given in Table 1.

Patients with COPD had significantly lower body weight, BMI and fat mass than did the control subjects. The COPD patients had severe airflow limitation, decreased $\mathrm{PaO}_{2}$ and increased $\mathrm{PaCO}_{2}$ values. The control subjects had normal $\%$ FVC and \% FEV1 on spirograms.

\section{Course of the parameters during the exacerbation Inflammatory parameters}

Compared to their concentrations in the healthy subjects, TNF- $\alpha$, IL-1 $\beta$, IL- 6 and IL- 8 were significantly higher in the patients with COPD on D1. By Day 15 cytokine levels did not differ from those of healthy controls with the exception of IL-8. Although IL-8 levels were decreased on D15 in COPD patients, they still significantly differed from healthy subjects (Table 2).

In COPD patients hospitalized due to an acute exacerbation, TNF- $\alpha$, IL- $1 \beta$, IL- 6 and IL- 8 levels on D1 were significantly higher compared to the levels measured on D15 (Table 2). 
Table I: Characteristics of the two groups

\begin{tabular}{|c|c|c|c|}
\hline & $\begin{array}{c}\text { COPD patients }(n=52) \\
43 \mathrm{M}, 9 \mathrm{~F} \\
(\text { Mean } \pm \text { SD })\end{array}$ & $\begin{array}{c}\text { Healthy subjects }(n=25) \\
19 M, 6 F \\
(\text { Mean } \pm \text { SD) }\end{array}$ & $\mathbf{p}$ \\
\hline Age, yr & $65,8 \pm 8,3$ & $65.9 \pm 9.6$ & 0.789 \\
\hline Weight, kg & $71,1 \pm 13,6$ & $77.2 \pm 10.1$ & 0.037 \\
\hline Height, cm & $166,48 \pm 7,11$ & $167.56 \pm 6.91$ & 0.669 \\
\hline BMI, $\mathrm{kg} / \mathrm{m}^{2}$ & $25,6 \pm 4,1$ & $27.9 \pm 4.1$ & 0.029 \\
\hline Fat mass, kg & $21,5 \pm 6,6$ & $25.9 \pm 7.3$ & 0.011 \\
\hline Fat free mass, kg & $49,6 \pm 9,0$ & $51,2 \pm 7,9$ & 0.427 \\
\hline$\% \mathbf{F M}$ & $29,8 \pm 5,1$ & $31.6 \pm 6.3$ & 0.211 \\
\hline FVC \%Pred & $62,4 \pm 14,3$ & $92.6 \pm 6.6$ & 0.000 \\
\hline FEV $\%$ Pred & $44, I \pm 1 I, 4$ & $89.9 \pm 8.0$ & 0.000 \\
\hline $\mathrm{PaO}_{2} \mathrm{mmHg}$ & $58,2 \pm 12,5$ & $87.6 \pm 4.6$ & 0.000 \\
\hline $\mathrm{PaCO}_{2} \mathrm{mmHg}$ & $47,1 \pm 10,8$ & $39.2 \pm 2.5$ & 0.000 \\
\hline
\end{tabular}

When COPD patients who received oxygen therapy were compared to those who did not, no difference in cytokine levels was detected.

Leptin

The levels of leptin in COPD patients with exacerbation were significantly higher on D1 and still on D15 com- pared to healthy subjects [33.3 (16.7-45.5)] ng/ml, p < 0.0001 and $[15.7(8.5-26)] \mathrm{ng} / \mathrm{ml}, \mathrm{p}=0.022$ respectively, versus $[9.6(4.5-13.7)] \mathrm{ng} / \mathrm{ml})$. Leptin concentration decreased significantly from D1 to D15 of the COPD exacerbation ( $\mathrm{p}<0.0001$ ). After dividing leptin by \%FM, the same pattern was seen. Thus, leptin/\%FM was significantly elevated on D1 and nearly significantly increased

Table 2: Concentrations of plasma cytokines, leptin and IGF-I in healthy controls compared to patients with COPD exacerbation on admission to the hospital (DI) and after two weeks (DI5)

\begin{tabular}{|c|c|c|c|}
\hline $\begin{array}{c}\text { Markers } \\
\text { Median (25-75 percentile) }\end{array}$ & $\begin{array}{l}\text { COPD patients (DI) } \\
(n=52)\end{array}$ & $\begin{array}{l}\text { Healthy subjects } \\
\quad(n=25)\end{array}$ & $\begin{array}{c}\text { COPD patients } \\
(D \mid 5) \\
(n=52)\end{array}$ \\
\hline TNF- $\alpha$ (pg/ml) & $63.9(46.7-84.5)^{*}+\dagger$ & $14(9.2-15.8)$ & $14.3(10.5-19.9)$ \\
\hline IL-I $\beta$ (pg/ml) & $12.5(8.8-16.9) * \dagger \dagger$ & $3.6(2.6-4)$ & $3.8(2.7-5.2)$ \\
\hline IL-6 (pg/ml) & $23(17.7-44.6) * \dagger \dagger$ & $9.7(7.5-12.3)$ & $10.6(6.5-14.9)$ \\
\hline IL-8 (pg/ml) & $39.8(29.2-56.3) *+\dagger$ & $13.7(10-19)$ & $18.5(12.3-24) \dagger$ \\
\hline Leptin (ng/ml) & $33.3(16.7-45.5) *+\dagger$ & $9.6(4.5-13.7)$ & $15.7(8.5-26) \dagger$ \\
\hline IGF-I (ng/ml) & $59.7(44.3-76) *+\dagger$ & $133.2(124-164.5)$ & $96.6(82.9-116.8) *$ \\
\hline Leptin/\% FM & I.I $(0.6-1.55) * \dagger \dagger$ & $0.30(0.16-0.43)$ & $0.5(0.26-0.94) *$ \\
\hline
\end{tabular}

Between healthy subjects and COPD patients $* p<0.01+p<0.05$ Between COPD patients DI and DI5 t† $p<0.01$ 
on D15 compared to healthy subjects $(\mathrm{p}<0.001$ and $\mathrm{p}=$ 0.008 respectively).

Insulin-like growth factor I (IGF-I)

Compared to its concentration in the healthy subjects [133.2 (124-164.5)] ng/ml), plasma IGF-I was significantly lower in COPD patients on D1 of the exacerbation and remained lower on D15 [59.7 (44.3-76)] ng/ml, p $<0.001$ and $[96.6(82.9-116.8)] \mathrm{ng} / \mathrm{ml}, \mathrm{p}<0.001$ respectively versus healthy subjects). IGF-I levels were significantly increased from D1 to D15 throughout the exacerbation $(\mathrm{p}<0.001)$.

\section{Chronic bronchitis and emphysema}

Characteristics of the study group stratified into the COPD subtypes (23 patients with emphysema and 29 patients with chronic bronchitis) are given in Table 3.

Patients with emphysema were characterized by a significantly lower FVC and FEV1 compared to those with chronic bronchitis. Emphysematous patients had also a significantly lower BMI owing to a significantly lower FM (mean difference $5.04 \mathrm{~kg}$ ). No difference was found in $\mathrm{PaO}_{2}$ and $\mathrm{PaCO}_{2}$ between patients with chronic bronchitis and emphysema.

No differences were seen in the concentrations of TNF- $\alpha$, IL-1 $\beta$, IL-6, IL-8, leptin and leptin/\% FM between the two

Table 3: Characteristics of patients with chronic bronchitis and emphysema

\begin{tabular}{lccc}
\hline & $\begin{array}{c}\text { Chronic bronchitis } \\
(\mathbf{n}=\mathbf{2 9}) \\
\mathbf{2 5} \mathbf{M}, \mathbf{4} \mathbf{~ F}\end{array}$ & $\begin{array}{c}\text { Emphysema } \\
(\mathbf{n}=\mathbf{2 3}) \\
\mathbf{1 8} \mathbf{M}, \mathbf{5} \mathbf{~ F}\end{array}$ & $\mathbf{p}$ \\
\hline Age, yr & $68.9 \pm 9.3$ & $70.8 \pm 7.0$ & 0.524 \\
\hline Weight, kg & $75.3 \pm 14.1$ & $65.9 \pm 11.4$ & $\mathbf{0 . 0 2 2}$ \\
\hline Height, cm & $166.44 \pm 7.10$ & $166.52 \pm 7.29$ & 0.971 \\
\hline BMI, kg/m ${ }^{2}$ & $27.1 \pm 4.2$ & $23.7 \pm 3.1$ & $\mathbf{0 . 0 0 3}$ \\
\hline \% FM & $31.4 \pm 4.5$ & $27.9 \pm 5.2$ & $\mathbf{0 . 0 4 7}$ \\
\hline Fat mass, kg & $23.7 \pm 6.4$ & $18.7 \pm 5.7$ & $\mathbf{0 . 0 0 6}$ \\
\hline Fat free mass, kg & $51,5 \pm 9,7$ & $47,2 \pm 7,7$ & 0.058 \\
\hline FVC \%Pred & $65.7 \pm 14.1$ & $58.1 \pm 13.8$ & $\mathbf{0 . 0 3 2}$ \\
\hline FEV \%Pred & $47.4 \pm 11.2$ & $39.2 \pm 9.9$ & $\mathbf{0 . 0 0 5}$ \\
\hline PaO ${ }_{2}$ mmHg & $59,4 \pm 13,3$ & $56,6 \pm 11,6$ & 0.256 \\
\hline PaCO ${ }_{2}$ mmHg & $49,6 \pm 12,0$ & $41,1 \pm 9,5$ & 0.276 \\
\hline
\end{tabular}

groups of patients on D1 and D15. On the contrary, IGFI was significantly lower in emphysematous patients compared to patients with chronic bronchitis both on D1 and D15 [49.5 (40.1-65.4)] versus [70.5 (48.6-78.5)] ng/ml, $\mathrm{p}=0.003$ on D1 and [84.7 (74.4-96.9)] versus [112.7 (92.4-124.1)] ng/ml, $\mathrm{p}<0.001$ on D15) (Table 4 and Table 5, Figure 1).

\section{Correlation analyses}

A strong correlation between leptin and \% FM was observed in controls $(\mathrm{r}=0.780, \mathrm{p}<0.001)$.

In order to elucidate the possible relationship of circulating cytokine levels with plasma leptin and IGF-I concentrations correlation analysis was performed on D1 and D15.

On D1 of the exacerbation, TNF- $\alpha$ demonstrated a significant positive correlation with leptin as well as with leptin adjusted to \% FM ( $\mathrm{r}=0.620, \mathrm{p}<0.001$ and $\mathrm{r}=0.650$, $\mathrm{p}<$ 0.001 )(Figure 2). This correlation between TNF- $\alpha$ and leptin was true even when we studied patients with chronic bronchitis and emphysema separately $(r=0.719$, $\mathrm{p}<0.001$ and $\mathrm{r}=0.505, \mathrm{p}=0.014$ respectively). TNF- $\alpha$ was also positively correlated with leptin/\% FM in both chronic bronchitis and emphysema $(\mathrm{r}=0.774, \mathrm{p}<0.001$ and $\mathrm{r}=0.499, \mathrm{p}=0.015$ respectively). Moreover, the change in TNF- $\alpha$ levels $(\Delta \mathrm{TNF}-\alpha)$ was significantly related to the change in leptin levels ( $\Delta$ Leptin) $(r=0.545, \mathrm{p}<$ 0.001 ).

On D15, no significant correlations could be revealed between any of the parameters.

IGF-I was not found to be related to any of the inflammatory cytokines neither on D1 nor on D15.

\section{Discussion}

The present study was performed to examine circulating levels of leptin and IGF-I at the onset of COPD exacerbations (D1) and two weeks later (D15) and furthermore to investigate the relationship of plasma leptin and IGF-I concentrations with cytokine concentrations as a possible reflection of the enhanced inflammatory status observed during the COPD exacerbation.

We found that COPD exacerbations are characterized by increased levels of leptin and the proinflammatory cytokines TNF- $\alpha$, IL- $1 \beta$, IL- 6 and IL- 8 and decreased levels of IGF-I on D1. We also found that two weeks after the onset of the exacerbation (D15) cytokine levels did not significantly differ from those of healthy subjects, with the exception of IL-8. IL-8 levels, although significantly decreased in COPD patients between D1 and D15, they still remained higher on D15 compared to healthy sub- 


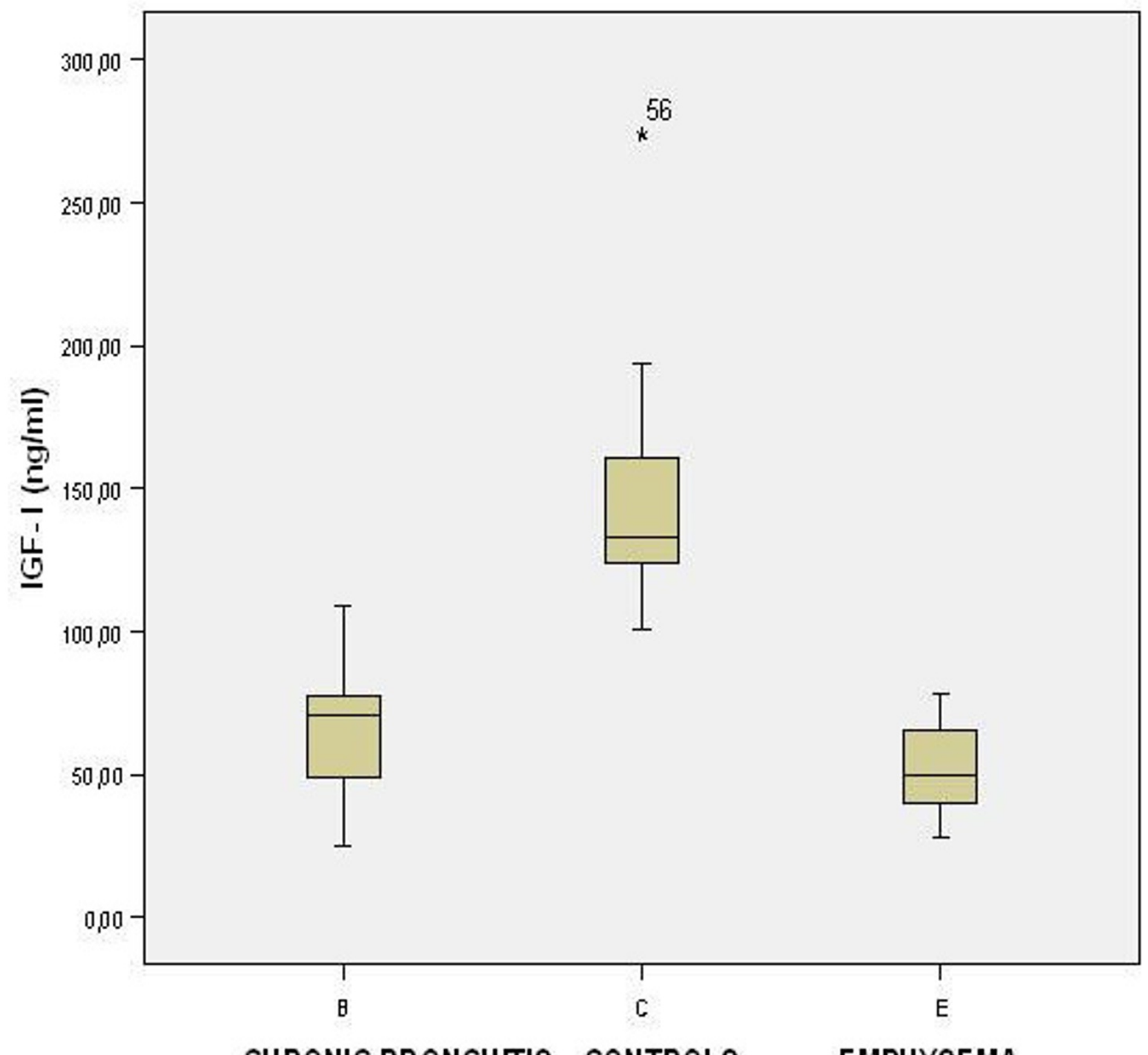

\section{CHRONIC BRONCHTIS CONTROLS EMPHYSEMA}

Figure I

IGF-I in chronic bronchitis (B), emphysema (E) and control group (C) on admission to the hospital (DI). Significant differences between $B-E(P=0.003), B-C(p=0.000)$ and $E-C(p=0.000)$

jects. Although circulating plasma leptin decreases and plasma IGF-I increases, they still remained different compared to healthy controls on D15. Leptin was positively related to TNF- $\alpha$ on D1 of the exacerbation and this correlation also applied to both subgroups of COPD patients, thus chronic bronchitis and emphysema. Finally, we found that IGF-I levels were significantly lower to emphysematous patients compared to patients with chronic bronchitis both on D1 and on D15. Leptin and cytokine levels did not differ between patients with chronic bronchitis and emphysema.

The elevated levels of TNF- $\alpha$, IL-1 $\beta$, IL- 6 and IL- 8 on admission to the hospital (D1), observed in our study are in keeping with numerous studies that have reported increased levels of circulating cytokines in the peripheral circulation of patients with COPD $[3,20,21]$. These abnormalities, albeit seen in clinically stable COPD patients, 
Table 4: Concentrations of plasma cytokines, leptin and IGF-I in patients with chronic bronchitis and emphysema on admission to the hospital (DI).

\begin{tabular}{|c|c|c|c|}
\hline $\begin{array}{c}\text { Markers } \\
\text { Median (25-75 percentile) }\end{array}$ & $\begin{array}{l}\text { Chronic bronchitis } \\
(n=29)\end{array}$ & $\begin{array}{c}\text { Emphysema } \\
\quad(n=23)\end{array}$ & $\mathbf{p}$ \\
\hline TNF- $\alpha(\mathrm{pg} / \mathrm{ml})$ & $63.2(45.5-85.7)$ & $65(47.2-80.2)$ & 0.612 \\
\hline IL-I $\beta$ (pg/ml) & $12.6(8.8-15.6)$ & | $2.3(8.4-2 \mid .3)$ & 0.941 \\
\hline IL-6 (pg/ml) & $23.9(19.7-40.4)$ & $20.6(15.9-52.6)$ & 0.423 \\
\hline IL-8 (pg/ml) & $39.7(28.9-56.2)$ & $42(34.3-62.7)$ & 0.574 \\
\hline Leptin (ng/ml) & $37.7(18.1-50.9)$ & $32.5(15.2-44.9)$ & 0.214 \\
\hline IGF-I (ng/ml) & $70.5(48.6-78.5)$ & $49.5(40.1-65.4)$ & 0.003 \\
\hline Leptin/\% FM & I.I (0.62-1.6I) & $1.09(0.6-1.55)$ & 0.619 \\
\hline
\end{tabular}

they are generally more pronounced during exacerbations of the disease [21]. The systemic inflammatory response is ameliorated 15 days after the onset of the exacerbation, as shown by the decrease in cytokine levels.

Circulating leptin levels were high on D1 of the exacerbation and remained elevated on D15 in COPD patients compared to healthy subjects. The elevated leptin concentrations during COPD exacerbation are in keeping with the results of other studies [7] and likely represented an up-regulation of leptin mRNA resulting in an enhanced leptin production that might have been induced by several factors. The positive correlation between leptin and TNF- $\alpha$ which was seen in our COPD patients on D1 of the exacerbation, supports an inflammatory-related disturbance in leptin metabolism in COPD. This correlation was true even when we studied separately the two subgroups of patients (chronic bronchitis - emphysema). It has been shown that the administration of endotoxin or cytokines such as TNF- $\alpha$ and IL- 1 can increase serum leptin levels both in hamsters and humans [8,9]. A positive correlation between leptin and soluble TNF- $\alpha$ receptors (sTNF-R55) was also found during COPD exacerbations in the study by Creutzberg et al [7]. In a recent study by Calikoglu et al serum leptin and TNF- $\alpha$ levels were increased in COPD patients with exacerbation in comparison to COPD patients with stable disease and healthy controls [22]. Moreover, and in accordance with our findings, a strong correlation between TNF- $\alpha$ and leptin was observed only in COPD patients with exacerbation but not in stable COPD patients and healthy individuals [22]. Takabatake et al recently reported that serum leptin levels

Table 5: Concentrations of plasma cytokines, leptin and IGF-I in patients with chronic bronchitis and emphysema on DI5.

\begin{tabular}{|c|c|c|c|}
\hline $\begin{array}{c}\text { Markers } \\
\text { (Median (25-75 percentile) }\end{array}$ & $\begin{array}{l}\text { Chronic bronchitis } \\
\quad(n=29)\end{array}$ & $\begin{array}{l}\text { Emphysema } \\
\quad(n=23)\end{array}$ & $\mathbf{p}$ \\
\hline TNF- $\alpha(\mathrm{pg} / \mathrm{ml})$ & $13.7(10.5-19.8)$ & $15.1(10.5-20.1)$ & 0.632 \\
\hline IL-I $\beta$ (pg/ml) & $3.9(3.4-5.8)$ & $3.7(2-4.7)$ & 0.273 \\
\hline IL-6 (pg/ml) & $10.6(7.4-14.1)$ & $10.4(5.8-16.2)$ & 0.706 \\
\hline IL-8 (pg/ml) & $17.9(\mid 1.8-23.2)$ & $19(12.3-26.6)$ & 0.612 \\
\hline Leptin (ng/ml) & I5.6 (7.9-28.6) & I5.7 (8.4-22.8) & 0.847 \\
\hline IGF-I (ng/ml) & II $2.7(92.4-124.1)$ & $84.7(74.4-96.9)$ & 0.000 \\
\hline Leptin/\% FM & $0.45(0.27-0.98)$ & $0.56(0.25-0.81)$ & 0.768 \\
\hline
\end{tabular}




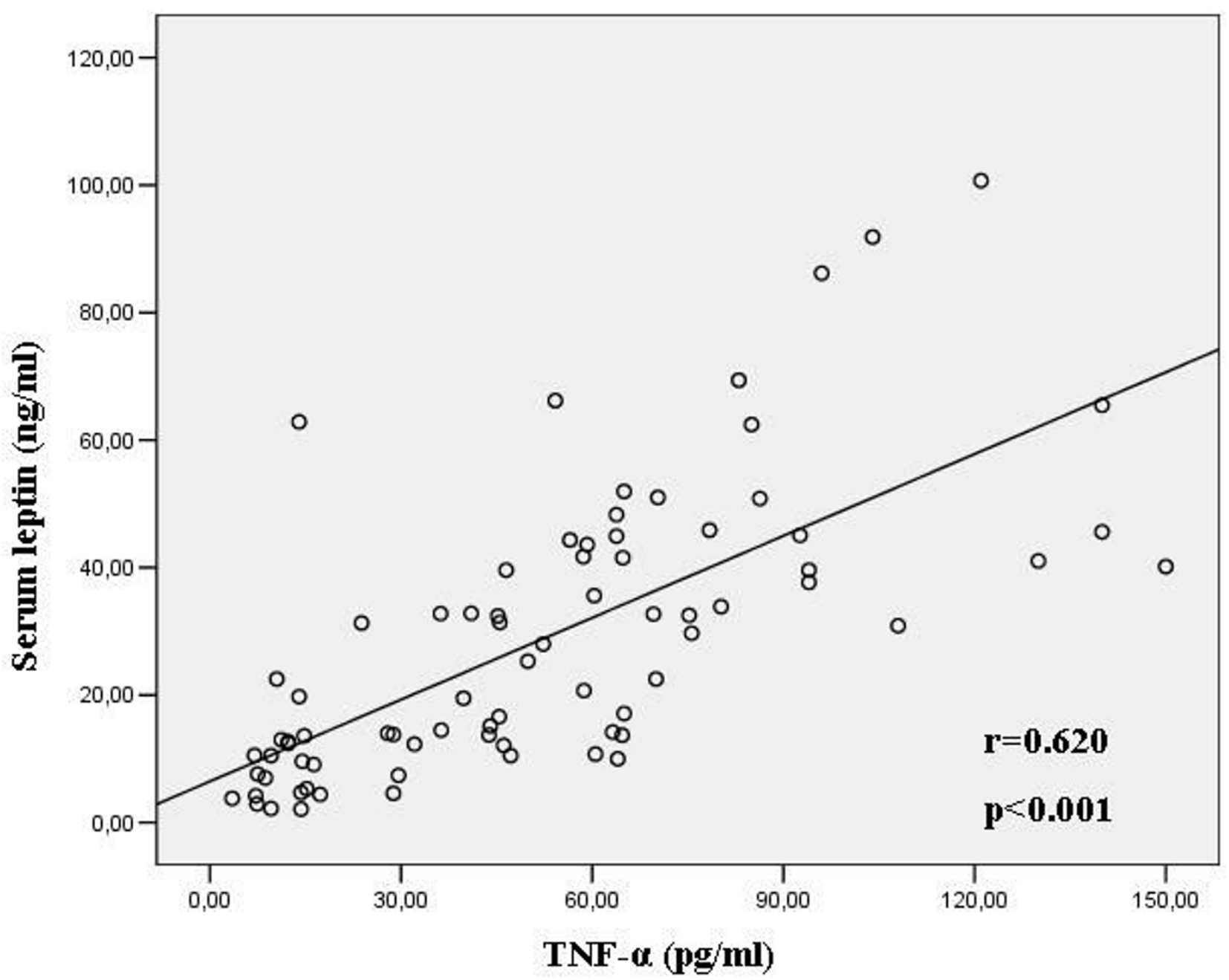

Figure 2

Leptin is significantly related to TNF- $\alpha$ in COPD patients on Day I of the exacerbation.

were significantly lower in COPD patients than healthy controls [23]. However, this study included patients with stable disease who were free of symptoms for at least three months. The relationship between the change in TNF- $\alpha$ levels $(\Delta T N F-\alpha)$ and the change in leptin levels ( $\Delta$ Leptin) observed in our study, further supports a TNF- $\alpha$-related disturbance in leptin during COPD exacerbations.

A reason for the high leptin concentrations might have been the glucocorticosteroid treatment and that presents a limitation of our study. Reports concerning the effects of corticosteroids on leptin are contradictory. Two days of oral dexamethasone $(1.5 \mathrm{mg} /$ day $)$ in healthy subjects resulted in significantly increased serum concentrations of leptin [24]. In another study, administration of dexamethasone for 4 days ( $2.5 \mathrm{mg} /$ day) to healthy subjects also induced a significant increase in plasma leptin concentrations [25]. Glucocorticosteroids may have a stimulating effect on leptin via the induction of insulin resistance, as glucose and insulin are also able to induce leptin expression [26]. However, Tataranni et al demonstrated that acute intravenous administration of glucocorticosteroids or prolonged oral treatment did not affect serum leptin levels [27]. Our COPD patients had severe airflow obstruction and it was necessary to introduce steroid treatment to improve their clinical status. However, samples on D1 were obtained before the first corticosteroid administration and on D15 7 days after the last intravenous administration of prednisolone, according to the protocol used. Regarding the effects of adrenergic stimulation on leptin metabolism, no studies have been performed with specific $\beta 2$-adrenergic stimulants such as 
salbutamol. Intravenous infusion of isoprenaline in young healthy volunteers resulted in a maximal suppression of plasma leptin of $20 \%$ of baseline values after $2 \mathrm{~h}$, but in the recovery period of $1 \mathrm{~h}$, leptin concentrations rapidly returned to normal [28]. In our study COPD patients received salbutamol by nebulizer and not intravenously.

Limited data is available regarding circulating levels of IGF-I in COPD. Growth hormone (GH) mediates its major metabolic effects predominantly through IGF-I [10]. The GH axis is suppressed in chronic diseases and this may partly explain the low IGF-I levels. However, increased concentrations of $\mathrm{GH}$ have been found in COPD patients, especially in those with hypoxaemia [29].

In our study, patients with COPD exacerbation had significantly lower IGF-I levels on D1 and also on D15 compared to healthy controls. Our finding of low IGF-I levels is compatible with other studies. Casaburi et al have also reported low levels of IGF-I in COPD patients [30]. Spruit et al found that IGF-I levels tended to be lower in patients with COPD exacerbation than in healthy subjects [12].

We are aware that the bioavailability and the effects of IGF-I are influenced by IGF-I binding proteins (IGFBP). Therefore, an increase in circulating levels of these proteins may decrease the levels of free IGF-I [31]. Cytokines increase IGFBP-1 and IGFBP-4 and this results in a decreased free IGF-I fraction. IL-6 performs its suppressive activity on IGF-I via increased production of its binding protein [32].

It is interesting to note that IGF-I levels were lower in patients with emphysema compared to those with chronic bronchitis, both at the onset of the exacerbation and 15 days later, whereas cytokine and leptin levels did not differ between the two subgroups. The decline in IGF-I levels may itself be deleterious. IGF-I mRNA levels were decreased in muscle biopsies from hospitalized patients due to an acute exacerbation of COPD [13]. Moreover, it has been demonstrated that pulmonary rehabilitation leads to an increase in muscle mRNA expression of IGF-I in COPD patients [33]. COPD patients often present with hypoxia during exacerbations. In animal studies, recombinant IGF-I has been shown to ameliorate the protein catabolism observed under hypoxic conditions and to promote anabolism [14]. The decreased levels of this anabolic factor, especially in emphysematous patients further enhance its possible role in metabolic derangements of COPD and mainly emphysema. The lower body weight, usually observed in patients with emphysema may be related to the lower IGF-I levels found in these patients, particularly during exacerbations. Low levels of anabolic hormones could act synergistically with the catabolic activity of cytokines and leptin and play a role in the weight loss and decreased muscular mass usually seen in COPD patients and mainly those with emphysema. This may also have important therapeutic implications, since an increase in anabolic factors in COPD patients, particularly during exacerbations may have a protective metabolic effect.

\section{Conclusion}

During an acute exacerbation of COPD, elevated levels of the proinflammatory cytokines TNF- $\alpha$, IL- $1 \beta$, IL- 6 and IL8 and increased levels of leptin and decreased levels of IGF-I are observed. It seems that, although systemic inflammation, in terms of cytokines, is restored relatively quickly, the coexistent disturbance of leptin and IGF-I is preserved for a longer period of time.

Lower levels of the anabolic factor IGF-I are observed in emphysema compared to chronic bronchitis and this may be related to the more pronounced metabolic derangements observed in this subgroup. Further studies are needed to elucidate the role of increased leptin and decreased IGF-I levels during COPD exacerbations and their possible relationship with energy imbalance observed in these patients.

\section{Competing interests}

The authors declare that they have no competing interests.

\section{Authors' contributions}

PK and PB conceived of the study, and participated in its design and coordination and drafted the manuscript. AK, $\mathrm{AH}$ and EA carried out the immunoassays. SA contributed to the acquisition of the data and the statistical analysis. AR participated in its design and drafted the manuscript. All authors read and approved the final manuscript.

\section{References}

I. Schols AMWJ, Soeters PB, Mostert R, Saris WHM, Wouters EFM: Energy balance in chronic obstructive pulmonary disease. Am Rev Respir Dis 1991, 143:1248-1252.

2. Vermeeren MAP, Schols AMWJ, Wouters EFM: Effects of an acute exacerbation on nutritional and metabolic profile of patients with COPD. Eur Respir J 1997, 10:2264-2269.

3. Di Francia M, Barbier D, Mege JL, Orehek J: Tumor necrosis factor-alpha levels and weight loss in chronic obstructive pulmonary disease. Am J Respir Crit Care Med 1994, I 50: I453-1455.

4. de Godoy I, Donahoe M, Calhoun W], Mancino J, Rogers RM: Elevated TNF-a production by peripheral blood monocytes of weight-losing COPD patients. Am J Respir Crit Care Med 1996, I 53:633-637.

5. Saetta M, Di Stefano A, Maestrelli P, Turato G, Ruggieri MP, Roggeri A, Calcagni P, Mapp CE, Ciaccia A, Fabbri LM: Airway eosinophilia in chronic bronchitis during exacerbations. Am J Respir Crit Care Med 1994, 150:1646-1652.

6. Schols AMW], Creutzberg EC, Buurman WA, Campfield LA, Saris WHM, Wouters EFM: Plasma leptin is related to proinflammatory status and dietary intake in patients with chronic obstructive pulmonary disease. Am J Respir Crit Care Med I999, 160:1220-1226.

7. Creutzberg EC, Wouters EFM, Vanderhoven-Augustin IML, Dentener MA, Schols AMW]: Disturbances in Leptin Metabolism Are 
Related to Energy Imbalance during Acute Exacerbations of Chronic Obstructive Pulmonary Disease. Am J Respir Crit Care Med 2000, 162:1239-1245.

8. Grunfeld C, Zhao C, Fuller J, Pollock A, Moser A, Friedman J, Feingold $K R$ : Endotoxin and cytokines induce expression of leptin, the ob gene product, in hamsters: a role for leptin in the anorexia of infection. J Clin Invest 1996, 97:2152-2157.

9. Zumbach MS, Boehme MWJ, Wahl P, Stremmel W, Ziegler R, Nawroth PP: Tumor necrosis factor increases serum leptin levels in humans. J Clin Endocrinol Metab 1997, 82:4080-4082.

10. Matthews LS, Norstadt G, Palmirez RD: Regulation of insulin-like growth factor-I gene expression by growth hormone. Proc Natl Acad Sci USA 1986, 83:9343-9347.

II. Scalvini S, Volterrani M, Vitacca M, et al.: Plasma hormone levels and haemodynamics in patients with chronic obstructive lung disease. Monaldi Arch Chest Dis 1996, 5 1:380-386.

12. Spruit MA, Gosselink R, Troosters T, Kasran A, Gayan-Ramirez G, Bogaerts $P$, Bouillon R, Decramer M: Muscle force during an acute exacerbation in hospitalised patients with COPD and its relationship with CXCL8 and IGF-I. Thorax 2003, 58(9):74I-742.

13. Crul T, Spruit MA, Gayan-Ramirez G, Quarck R, Gosselink R, Troosters T, Pitta F, Decramer M: Markers of inflammation and disuse in vastus lateralis of chronic obstructive pulmonary disease patients. Eur J Clin Invest 2007, 37:897-904.

14. lioka Y, Tatsumi K, Sugito K, Moriya T, Kuriyama T: Effects of insulin-like growth factor on nitrogen balance during hypoxic exposure. Eur Respir J 2002, 20:252-253.

15. Burdet L, de Muralt B, Schutz Y, Pichard C, Fitting JW: Administration of growth hormone to underweight patients with chronic obstructive pulmonary disease. A prospective, randomized controlled study. Am J Respir Crit Care Med 1997, I56:1800-1806

16. GOLD: Global Initiative for chronic obstructive lung disease. Global strategy for the diagnosis, management and prevention of chronic obstructive pulmonary disease. NHLBI/WHO, Workshop report; 2006.

17. Lukaski HC, Johnson PE, Bolonchuk WW, Lykken Gl: Assessment of fat-free mass using bioelectrical impedance measurements of the human body. Am J Clin Nutr 1985, 41:810-8I7.

18. Quanjer PH, editor: Standardized lung function testing. Eur Respir J 1993, 6(Suppl 16): I-52.

19. Sakai F, Gamsu G, Im JG, Ray CS: Pulmonary function abnormalities in patients with CT-determined emphysema. J Comp Assist Tomogr 1987, I I:963-968.

20. Schols AM, Buurman WA, Brekel AJ Staal-van den, Dentener MA, Wouters EFM: Evidence for a relation between metabolic derangements and increased levels of inflammatory mediators in a subgroup of patients with chronic obstructive pulmonary disease. Thorax 1996, 51:819-824.

21. Agusti AGN, Noguera A, Sauleda J, Sala E, Pons J, Busquets X: Systemic effects of chronic obstructive pulmonary disease. Eur Respir J 2003, $21: 347-360$

22. Calikoglu M, Sahin G, Unlu A, Ozturk C, Tamer L, Ercan B, Kanik A, Atik U: Leptin and TNF-alpha levels in patients with chronic obstructive pulmonary disease and their relationship to nutritional parameters. Respiration 2004, 7 I:45-50.

23. Takabatake $N$, Nakamura $H$, Abe $S$, Hino T, Saito $H$, Yuki $H$, Kato $S$, Tomoike $\mathrm{H}$ : Circulating leptin in patients with chronic obstructive pulmonary disease. Am J Respir Crit Care Med 1999, 159:1215-1219.

24. Papaspyrourao S, Schneider SH, Petersen RN, Fried SK: Dexamethasone increases leptin expression in humans in vivo. J Clin Endocrinol Metab 1997, 82(5):1635-1637.

25. Dagogojack S, Selke G, Melson AK, Newcomer JW: Robust leptin secretory responses to dexamethasone in obese subjects. Clin Endocrinol Metab 1997, 82:3230-3233

26. Schols AMWJ, Soeters PB, Mostert R, Pluymers RJ, Wouters EFM: Physiological effects of nutritional support and anabolic steroids in COPD patients. Am J Respir Crit Care Med 1995, I 52: 1268-1274.

27. Tataranni PA, Pratley R, Maffei M, Ravussin E: Acute and prolonged administration of glucocorticoids (methylprednisolone) does not affect plasma leptin concentration in humans. Int J Obesity 1997, 21:327-330.
28. Pinkney JH, Coppack SW, Mohamed-Ali V: Effects of isoprenaline on plasma leptin and lipolysis in humans. Clin Endocrinol 1998, 48:407-4II

29. Hjalmarsen A, Aasebo U, Birkeland K, Sager G, Jorde R: Impaired glucose tolerance in patients with chronic hypoxic pulmonary disease. Diabetes Metab 1996, 22:37-42.

30. Casaburi R, Goersen S, Blasin S, et al:: Substantial prevalence of low anabolic hormone levels in COPD patients undergoing rehabilitation [abstract]. Am J Respir Crit Care Med 1996, I53:AI 28.

31. Benbassat CA, Maki KC, Unterman TG: Circulating levels of insulin-like growth factor (IGF) binding protein- $I$ and -3 in aging men: relationships to insulin, glucose, IGF, and dehydroepiandrosterone sulfate levels and anthropometric measures. Clin Endocrinol Metab 1997, 82: | 484-|49|.

32. Benbassat CA, Lazarus DD, Cichy SB, Evans TM, Moldawer LL, Lowry SF, Unterman TG: Interleukin-I alpha (IL-I alpha) and tumor necrosis factor alpha (TNF alpha) regulate insulin-like growth factor binding protein-I (IGFBP-I) levels and mRNA abundance in vivo and in vitro. Horm Metab Res 1999 , 3I:209-2I5.

33. Vogiatzis I, Stratakos G, Simoes DC, Terzis G, Georgiadou O, Roussos C, Zakynthinos S: Effects of rehabilitative exercise on peripheral muscle TNF alpha, IL-6, IGF-I and MyoD expression in patients with COPD. Thorax 2007, 62:950-956.

\section{Pre-publication history}

The pre-publication history for this paper can be accessed here:

http://www.biomedcentral.com/1471-2466/9/11/prepub

Publish with BioMed Central and every scientist can read your work free of charge

"BioMed Central will be the most significant development for disseminating the results of biomedical research in our lifetime. "

Sir Paul Nurse, Cancer Research UK

Your research papers will be:

- available free of charge to the entire biomedical community

- peer reviewed and published immediately upon acceptance

- cited in PubMed and archived on PubMed Central

- yours - you keep the copyright
BiolMedcentral 